\title{
Frequency of Occult Hepatitis B Virus (HBV) in Chronic Hepatitis C Patients
}

\author{
Waquaruddin Ahmed, Ijaz Hayder, Shaimuna Fareeha Sajjad and Syed Ejaz Alam \\ Department of Gastroenterology and Hepatology, Pakistan Health Research Council and Research Centre, JPMC, Karachi, Pakistan
}

\begin{abstract}
Occult HBV is defined as the presence of HBV DNA in the liver tissue and / or HBV DNA in blood of people with negative HBsAg by currently available assays. The objective of the study was to determine the prevalence of occult HBV in chronic HCV patients. It was a cross-sectional study of one year duration including patients coming to the outpatient department with a positive HCV RNA by PCR from May 2018 to May 2019. Blood samples were taken to test HBsAg. Those cases who were HBsAg negative were checked for HBV DNA using real time PCR. A total of 217 cases were included in the study. Mean age was $41.3 \pm$ 14.61 years. All 217 cases of chronic HCV infection, which were positive for HCV RNA by PCR, were found to be negative for both HBsAg and HBV DNA. No occult HBV was detected in cases of chronic HCV infection seeking treatment.
\end{abstract}

Key Words: Occult, Hepatitis B, Chronic hepatitis C.

How to cite this article: Ahmed W, Hayder I, Sajjad SF, Alam SE. Frequency of Occult Hepatitis B Virus (HBV) in Chronic Hepatitis C Patients. J Coll Physicians Surg Pak 2020; 30(10):1105-1106.

Occult hepatitis $B$ virus infection is the presence of HBV genome in the liver tissue without HBsAg positivity. It is defined as the presence of HBV DNA in the liver tissue and or HBV DNA in blood of people with negative HBsAg by currently available assays. However, presence of anti-HBc IgG antibodies in the blood is often used as a surrogate marker for occult HBV. ${ }^{1}$ Its prevalence is quite variable and it depends on the level of endemic disease in the community. It also depends on the different assays used for the study and different cohort of patients studied. The prevalence of occult HBV is higher in populations with high risk of HBV infection and patients of chronic liver disease than in the population where the risk of $\mathrm{HBV}$ infection and chronic liver disease is low. Since the route of transmission are same for hepatitis B and C, frequency of occult HBV is high in HCV infected patients $33 \%$ as compared to those not infected with HCV infection. ${ }^{2}$

It is still controversial as to whether occult HBV infection has any clinical significance. Several reports have suggested its potential effect on the progression of liver disease by reactivation of occult HBV and also in the development of hepatocellularcarcinoma. ${ }^{2}$

Correspondence to: Dr. Shaimuna Fareeha Sajjad, Department of Gastroenterology and Hepatology, Pakistan Health Research Council and Research Centre, JPMC, Karachi, Pakistan

E-mail: fareehaather@yahoo.com

Received: June 28, 2019; Revised: February 19, 2020;

Accepted: March 09, 2020

DOI: https://doi.org/10.29271/jcpsp.2020.10.1105
A study reported the significance of detecting occult HBV in HCV positive cirrhotic patients awaiting liver transplant in which the authors showed concern on chances of flare-up of HBV infection due to immunosuppressants that are used after liver transplant and suggested that this complication can be prevented by using appropriate prophylactic measures like nucleoside analogue therapy. ${ }^{3}$ Occult HBV in HCV cirrhosis patients, who are undergoing orthotropic liver transplant, has been reported to be $64 \% .{ }^{1} \mathrm{~A}$ local study from Islamabad, found occult HBV infection in $7.3 \%$ patients having $\mathrm{HCV}$ related chronic liver disease. ${ }^{4}$ The frequency of occult HBV in patients who are awaiting or have undergone liver transplantation is expected to be more than the general population because these end-stage liver disease patients are more likely to be exposed to invasive procedures like injections, repeated transfusions and different invasive procedures like paracentesis. In Pakistan, the prevalence of occult HBV in HCV infected patients is poorly known. Therefore, this study was conducted to find out the actual frequency of occult HBV in chronically infected HCV patients.

This was a prospective cross-sectional study conducted for a duration of one year from May 2018 to May 2019. After taking informed consent, patients coming for treatment of chronic HCV infection in the Outpatient Department of Pakistan Health Research Council, Research Centre, Jinnah Postgraduate Medical Centre were included in the study. Patients co-infected with either HIV or HBsAg were excluded. Blood samples were taken for HBsAg and HBV DNA by PCR. HBsAg test was run through ELISA using Dia Sorin Murex HBs Ag Version 3 kit. HBV DNA was extracted through QIA amp DSP virus kit and amplification was done on Qiagen kit through real time PCR Assay. 
The lower limit of HBV DNA detection was $3.8 \mathrm{IU} / \mathrm{ml}$. Chronic $\mathrm{HCV}$ patients who were HBsAg negative and HBV DNA positive were labelled asoccult hepatitis $B$.

A total of 217 anti-HCV and HCV RNA positive cases were included in the study. Mean age was $41.3 \pm 14.61$. There were $114(52.5 \%)$ males and 103 (47.5\%) females. All 217 cases were anti- HCV and HCV RNA positive while HBsAg was non-reactive. HBV-DNA was not detectable in any of these cases, i.e. there were no occult HBV cases in this series. There were 114 (52.5\%) males and 103 (47.5\%) females.

This study was conducted to determine the frequency of occult hepatitis HBV in chronic HCV patients. There is scarce data from Pakistan on this topic. It was found that there were no HBV DNA positive patients in our series of chronic HCV patients. Another study shows a very low frequency of occult HBV patients, i.e. $1 \%$. As the frequency was very low, i.e. just $1 \%$, this study does not recommend routine testing of HBV DNA in chronic HCV patients. ${ }^{5}$

This is in contrast to a previous study in transplant candidates, which showed a frequency of $7.3 \%$. A reason for this difference may be that most patients in the study were cirrhotic patients with multiple exposures to both viruses due to multiple therapeutic procedures or transfusions; whereas, our patients were probably in the early stages of liver disease. Studies conducted from other regions of the world contradict our results. A Korean study on healthy participants reported a prevalence of $16 \%$. Hui et al. reported a prevalence of $15 \%$ occult HBV genomes in hematopoietic stem cell donors from Hongkong. However, Rosa et al. reported a very low frequency of occult hepatitis $B$ (3.3\%) among HCV patients. ${ }^{2}$ An Iranian study on HCV patients, treated with pegylated interferon and ribavirin, showed that $30 \%$ patients were having occult HBV infection. The same study showed that $20 \%$ of people with occult hepatitis B infection were negative for all serological markers; whereas, $80 \%$ showed previous infection. ${ }^{6} \mathrm{~A}$ positive aspect in this respect is that most of the studies on occult HBV show low levels of HBV DNA. But the infection persists in a very mild form and may favour progression to cirrhosis even hepatocellular carcinoma. ${ }^{2}$ However, an American study shows no risk of HCC in HCV patients with occult HBV infection.

This study has a few limitations. First, liver biopsy was not conducted to determine the presence of HBV DNA in the liver tissue. Secondly, as HBV DNA appears to be intermittently in the blood, DNA testing could have been performed more than once. Nonetheless, this study is one of the few studies from
Pakistan on the subject. We recommend that more studies should be conducted to determine the frequency of occult HBV infection in chronic HCV patients in different stages of disease and different sub-groups of patients.

\section{PATIENTS' CONSENT:}

Informed consents were obtained from all patients to publish data in thisstudy.

\section{CONFLICT OF INTEREST:}

The authors have no conflict of interest to declare.

\section{AUTHORS' CONTRIBUTION:}

WA: Conceived the idea and designed the project; also contributed significantly to manuscript writing and interpretation of data.

$\mathrm{EH}:$ Involved in data collection and data compilation.

SFS: Contributed in all stages of manuscript writing and interpretation of data.

SEA: Performed the statistical analysis.

All authors read and approved the final version of the manuscript.

\section{REFERENCES}

1. Raimond G, Locarnini S, Pollicino T, Levrero M, Zoulim F, Lok AS. Update of the statements on biology and clinical impact of occult hepatitis B virus infection. J Hepatolo 2019; 7(2):397-408. doi: 10.1016/j.jhep.2019.03.034.

2. Gutiérrez-García ML, Fernandez-Rodriguez CM, LledoNavarro JL, Buhigas-Garcia I. Prevalence of occult hepatitis B virus infection. World J Gastroenterol 2011; 17 (12):1538-42. doi: 10.3748/wjg.v17.i12.1538.

3. Bhamidimarri KR, Pan C. Hepatitis B reactivation during immunosuppression: From pathogenesis to management strategy. N A J Med Sci 2011; 4:44-9.

4. Bal T, Onlen $Y$. The prevalence of occult hepatitis $B$ in chronic hepatitis $C$ patients treated with interferon-based antiviral therapy. Arab J Gastroenterol 2018; 19(1):33-6. doi: 10.1016/j.ajg.2018.02.001.

5. Vakili Ghartavol Z, Alavian SM, Amini S. Prevalence of occult hepatitis $B$ virus in plasma and peripheral blood mononuclear cell compartments of patients with chronic hepatitis C infection in Tehran-Iran. Hepat Mon 2013; 13(5):e10134. doi: 10.5812/hepatmon.10134.

6. Lok AS, Everhart JE, Di Bisceglie AM, Vahabpour R, Bahramali G, Mostafavi $E$, et al. Occult and previous hepatitis $B$ virus infection are not associated with hepatocellular carcinoma in United States patients with chronic hepatitis C. Hepatology 2011; 54(2):434-42. doi: 10.1002/hep.24257. 